\title{
A Global Software Engineering Knowledge Management Approach for INTENSIVE Risk Mitigation
}

\author{
Shruti Patil ${ }^{1}$ and Roshani Ade ${ }^{2}$ \\ ${ }^{1}$ Department of Computer Engineering, Dr. D. Y. Patil School of Engineering \\ \&Technology, Savitribai Phule Pune University, Pune, Maharashtra, India \\ ${ }^{2}$ Department of Computer Engineering, Dr. D. Y. Patil School of Engineering \\ \&Technology, Savitribai Phule Pune University, Pune, Maharashtra, India
}

\begin{abstract}
There is a necessity of formal risk management. A formal risk management procedure gives numerous profits to both the project group and the improvement association in general. Initially, it provides for them an organized component to give conceivability into dangers to project triumph. By acknowledging the potential effect of each one risk thing, we can concentrate on regulating the most intense risks first. We can convey risk evaluation with project estimation to quantify a conceivable schedule slippage if certain risks emerge into issues. Knowledge Management currently gets more considerations because of its assurance that learning from the past will generally assist software engineers make good decisions in uncertainty.

This methodology helps the project supervisor creates sensible possibility supports. The point when data requirements are different than actual requirements, either as a result of wrong SRS understandings or mid-requirement changes to SRS as part of the requirement updating are occupied, excessively troublesome to use, excessively challenging to decipher, or they essentially do not introduce of service or significant data, chiefs should principally depend on experience and instinct for discriminating choice making.
\end{abstract}

\section{KEYWORDS}

Knowledge management, Global Software development, Software engineering, Requirement management

\section{INTRODUCTION}

Global Software development is learning and individuals escalated action. Individuals in such gatherings must work together, convey, and coordinate their work, which makes learning management a need. Point of the fact, little and stable associations where workers are inside an arm's compass of one another can most likely make without information management. In any case, for associations that are huge and appropriated, whose environment is consistently changing, or have a high turnover, dealing with their information stakes are basic for survival.

A normal for software engineering that ends up being favourable element over different businesses as far as overseeing erudite capital is that curious are as of now caught in electronic structure and can undoubtedly be put away and imparted. Moreover, software regularly builds have a benevolent demeanour towards utilizing innovation. This implies that a software association that actualizes an information management framework could have a decent opportunity to succeed with this mission. However, this remaining parts a testing errand in light of the fact that a learning management framework is more than simply innovation. Expertise 
International Journal of Managing Public Sector Information and Communication Technologies (IJMPICT) Vol. 6, No. 1, March 2015

management, record management, and software reapplication are knowledge management activities that carry software development process. $[1,2]$.

\section{Sharing Process And Product Knowledge}

Software engineering is a complex business that includes numerous individuals are working in diverse stages and exercises. Steady innovation progressions make the work dynamic: New issues are illuminated, and new information is made consistently. The information in software engineering is different and its extents massive and developing. Associations have issues staying informed regarding what this learning is, the place it is, and who has it. An organized method for dealing with the information and treating the learning and its holders as important holdings could help associations influence the information they have. This area examines software associations' necessities identified with learning management. We likewise examine a percentage of the difficulties that software associations may confront when they attempt to execute learning management and in addition a few open doors that may make usage less demanding [3].

Every software item and procedure are distinctive as far as objectives and connections. A solitary software improvement approach can't be accepted for all tasks or items. To create software for the space shuttle is not the same as to create software for a dishwasher. Software engineers are regularly presented to these differences, which makes the software teaches intrinsically trial and us continual addition experience with every improvement venture. "Knowledge emerges in work practices; often being defined by the first project to address the issues involved"[4].

Conceivably, we would apply that encounter to future tasks with a specific end goal to dodge errors and influence triumphs. It does not happen in light of the fact that frequently these work practices are not caught. Development groups take a shot at comparative sorts of tasks without understanding that comes about would have been attained all the more effortlessly on the off chance that they emulated a practice embraced by a past task. How the money adds up is that development groups don't profit from existing background. Rather they rehash botches again and again.

This was showed by the way that "an extensive number of cases indicated an absence of learning in the particular venture, while this information was accessible in the organization". These issues are likewise attached to the issue of exchanging learning to amateurs in the association [5].

Learning Management addresses the issues of catching and imparting information, during the issues of undertaking differences and item peculiarity makes it clear that such a framework must be adaptable. Most antiques managing a software extend and created throughout a software task could be spoken to as reports. Subsequently, these are the primary express possessions of the software association. These benefits straightforwardly help the centre business and must be overseen so they don't get lost. The issues of exchanging information from masters to amateurs are encouraged if the learning is promptly caught, put away and sorted out, potentially as records. Consequently, Document Management is the fundamental foundation of our information management model $[6,7,8]$.

\section{Challenges}

Executing information management in any association is a test on account of the time and exertion that is needed before it begins to profit for the speculation. Software associations appear to have even less time than others due to the quick pace of the business. The absence of time is an immediate danger against learning management. The illustration is that "the master was so included in his or her anticipate that there was no time to backing the other undertaking" [9]. 
Individuals frequently have no time to try and quest for information. This social conduct has the impact that a long haul financing, for example, information management and learning for the following undertaking is not prioritized. Rather, extend supervisors are intrigued by completing the current extend on time. As long as management does not permit the society to change and does not permit representatives to put resources into dealing with their information, learning management is likely not to happen.

The most dangerous test to learning management is that the vast majority of the information in software engineering is unsaid and will never get express. It will stay unsaid in light of the fact that there is no time to make it unequivocal. There are not many methodologies and apparatuses for transforming implied information into express learning, and the majority of the unsaid learning is inferred in the most amazing way. Along these lines, it is hard to express and make unequivocal. An approach to address this issue could be to create information offering society, and also innovation help for learning management, always remembering that the principle stake of the association is its workers [10].

\section{The View Of Nonaka}

Unlike to different merchandise, information is advanced when imparted and is not reduced through utilization. With the end goal learning should be exchanged between people, it should first be changed into data (externalized), and after that changed over from data again to the information as appeared.

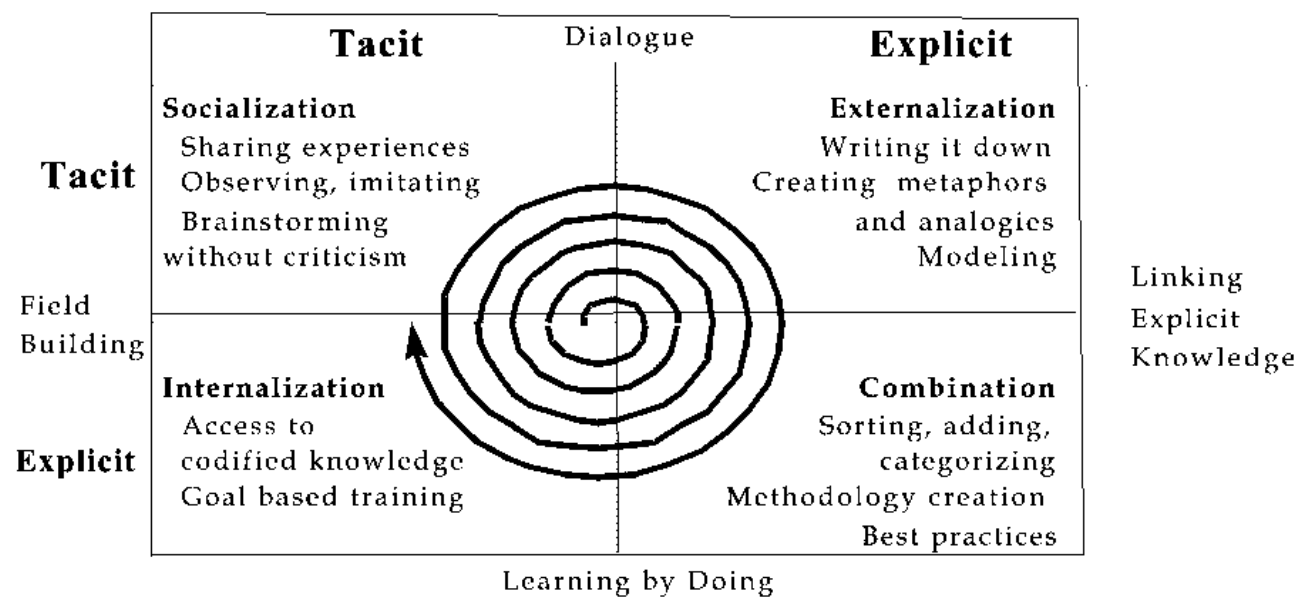

Figure 1. Nonaka's spiral of knowledge

Figure 1. For Nonaka implicit and unequivocal information are not separate however commonly integral substances. They communicate with one another in the innovative exercises of people. Nonaka calls the connection of these two types of information the learning change process $[11,12]$.

This transformation procedure comprises of four stages: socialization, externalization, mixture and disguise. The main step, socialization, exchanges implied learning between people through perception, impersonation and practice. In the following step, externalization is activated by dialog or aggregate reflection and depends on similarity or representation to make an interpretation of unsaid information into records and strategies.

Mixture subsequently reconfigures assemblages of unequivocal learning through sorting, including, joining together and classifying methodologies and spreads it all through an 
International Journal of Managing Public Sector Information and Communication Technologies (IJMPICT)

Vol. 6, No. 1, March 2015

association. In conclusion, disguise makes an interpretation of unequivocal information into individual unsaid learning. In the long run, through the marvel that Nonaka calls the "knowledge spiral," information creation and offering get to be a piece of the society of an association. Nonaka stresses that; the imparting of tacit learning happens through joint exercises and requires physical proximity. He likewise states that with the end goal others should comprehend it implicit learning must first be externalized [13].

\section{Global Software EngineEring TASKs AND ToOlS}

Birk et. Al. (2014) delineates the wide range of software engineering techniques that may happen in a regular software engineering venture [14]. What is basic amongst the results from all these methods and exercises is that they are all documents. The work is, ordinarily, centred on creating, looking into, altering, and utilizing these archives. Because of the way that numerous software associations are disseminated over huge geographic zones, these reports need to be remotely accessible. Since software engineering is so overwhelmed by the records that are created throughout the different exercises and courses of action, the establishment for an information management framework is a document management system.

Data management could be performed utilizing customarily office computerization apparatuses for email, assignment management, and, booking. An illustration of such a framework is Microsoft Outlook in consolidation with Microsoft Exchange Server. General data frameworks, be that as it may, fall outside of the extent of this report and are not examined further.

Requirement management frameworks have been utilized for a long while, however as the term information management got well known, there was an inclination to re-name the report management apparatuses as learning management instruments, to suit the new pattern. Requirements Assistants are instruments utilized by requirements experts to assess framework requirements and arrange it in formal details. These devices likewise help in requirements obtaining from the client, in the long run to assist with changing requirements and poorly characterized determinations [21,22].

Requirements teams consolidate information about provision spaces, framework segments, and configuration courses of action and help investigators in applying this learning to the requirements examination process. Different apparatuses like KBRAS help reusability of software segments by ordering and recovering requirements procured for other software provisions. Detail associates, when joined with requirements aides; bring about frameworks like ARIES that help the building of a determination through reuse of formerly characterized particulars from an information base. These apparatuses help exchange learning from the client to the seller. They likewise help in obtaining information about area particular requirements, which could be utilized within last ventures $[15,23,24,25]$.

Information gathered from tasks can additionally be in a qualitative structure, for example, cases and circumstance particular lessons learned; achievement and disappointment stories; and issues and relating results. This information might be spoken to in content arrangement, or all the more formally as standards, filed cases, semantic systems, and so forth [16,17]. Applying generalization and reflection on this information, we can produce learning that could be connected to other comparable settings. This is the means by which examples, best practice rules, handbooks, and measures might be inferred. Artificial intelligence strategies and machine learning calculations are constantly utilized for information revelation and securing. 


\section{Knowledge Management To Avoid Global Software Project RISK}

It is vital to gain from disappointments and oversights. An examination of Knowledge management (KM) disappointment reasons uncovers that a few clients oversee records rather than compelling learning. This is effectively done, on the grounds that the majority of the KM instruments available location record management as opposed to information management.

An alternate issue identifies with the way that not everything might be overseen by a KM framework [18,19]. On the off chance that everything is dumped into a typical storehouse, the measure of information to be overseen gets to be insensible and the majority of it might be futile. The last disappointment reason specified by Rigby is identified with the way that clients did not focus their objectives and technique before executing KM frameworks. Truth be told 50-60 percent of all KM organizations fizzled in light of the fact that numerous associations did not gangs a decent KM arrangement procedure or methodology, if any. Subsequently, financial and organizational costs swamped the benefits, usually as a result of inadequate attention to strategic priorities [20].

Also, it will be tricky to get acknowledgement from representatives if the innovation is seen as restricting the hierarchical society. In the event that the new engineering could be presented in a manner that is in accordance with the hierarchical society, then the activity has a much higher opportunity to succeed. Having these difficulties, snags, and disappointments as a primary concern, this area will concentrate on the social issues of actualizing a KM framework. It will examine diverse prize frameworks, give a sample of a strategy for actualizing a KM, and incorporate an arrangement of achievement elements for executing KM frameworks [19]. Figure 2 shows the cycle of KM. These three steps form a cycle which services knowledge evolution. Software engineering contains some knowledge forms like technical, administrative, business, product, project, and domain knowledge. Knowledge could be conveyed through proper training or learning.

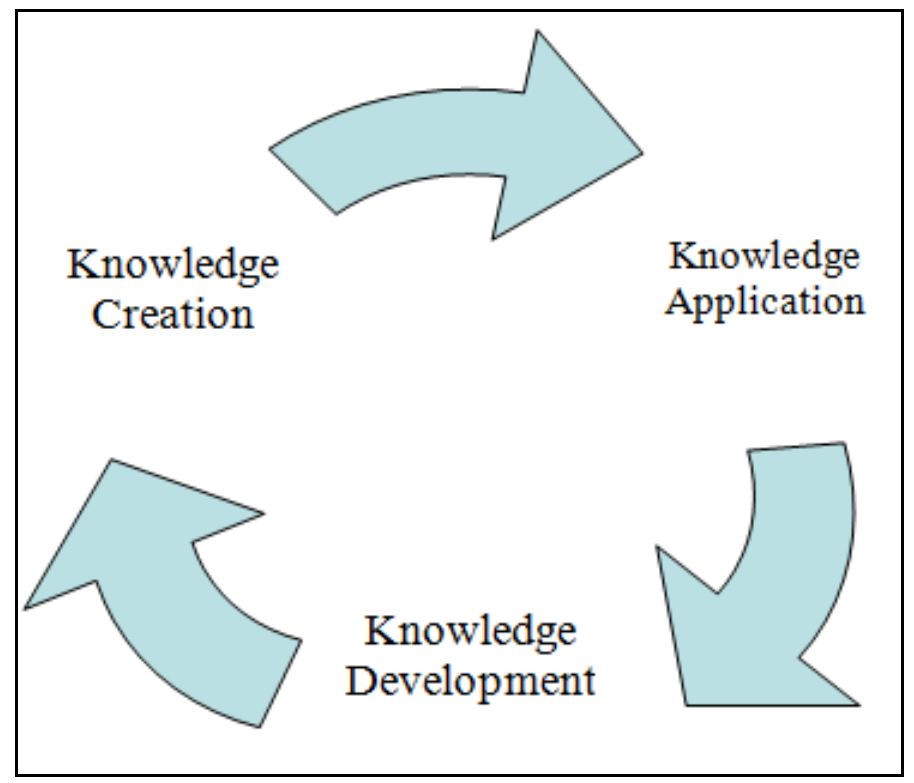

Figure 2. Knowledge Management Framework 
International Journal of Managing Public Sector Information and Communication Technologies (IJMPICT) Vol. 6, No. 1, March 2015

\section{NeW APPROACh: Agile Management System}

As expressed at the start of this segment, having a philosophy to guide the execution of any framework is a discriminating component of any KM program. We give a case of such an approach, in particular the usage of an Experience Management System that is applicable to any experience-based and learning based methodology. Distinctive associations have diverse needs and societies and that is the motivation behind why every Agile Management System (AMS) usage needs to be custom-made to the target association. The AMS approach addresses this issue and aides in the comprehension and setup of an AMS for any particular association. The system aides characterize the substance, structure, strategies and apparatuses that will be a piece of the AMS. The cooperation of individuals from the association in the requisition of the philosophy is urgent for the achievement of the AMS usage in light of the fact that such an activity can't be effective without people groups' help, commitment, and utilization. They are likewise the ones who know their society and issues best and can help evade snags and go for taking care of the genuine issues. The accompanying is a portrayal of the philosophy steps for creating an AMS for a specific association and area of encounters. It is focused around best practices determined from different past AMS ventures and has been consistently moved forward.

The principal step is a characterization of the association and meaning of current business techniques and existing learning. A refinement is made between learning that is recorded, undocumented and occupied. Numerous associations as of now have strategies set up to oversee detached subsets of their experience, however neglect to deal with all urgent experience. The characterization aides comprehend what experience is not secured how existing recorded experience fits the new framework, and how it could be reused.

After the characterization of the association, parts for the AMS clients are characterized, and utilization cases are produced focused around business methodologies and client parts. Client parts are characterized focused around the society of the association and the kind of parts that will be performed by distinctive individuals. Cases of client parts are supplier; purchaser, and maintainer. Client parts could be refined for every primary classification. An illustration of this refinement is point administrators, determined from maintainer and characterized as any individual who is in charge of upkeep of encounters identified with a particular subject. Utilization cases are characterized focused around the characterization of the association, the business forms that are significant to the AMS and the client parts. The utilization cases spread methodology that are now set up and include new ones as vital. The following step is to characterize an information model, or taxonomy, which is suitable for the association. The information model is utilized to depict and order the encounter that will be incorporated in the AMS so as to make it less demanding for clients to recover the experience. In this step, diverse sorts of encounter that will be overseen are distinguished and grouped. An adequate quality for every part of the information model is likewise characterized. The after-effects of this step are recorded in an AMS Requirements Document.

In the light of the AMS Requirements Document, the structural planning of the AMS is characterized. COTS and in-house development segments that, together, satisfy the requirements are utilized to characterize the structural planning. Provisions officially set up and utilized by the association are unequivocally considered to be a piece of the building design. The construction modelling is then executed. Apparatuses supporting the AMS are produced, introduced and coordinated.

After execution, a set of methodology for the general support of the AMS is conveyed. These systems are fixed to the client parts and will verify that the framework works and that oversaw experience is constantly up and coming. Figure 3 Shows the KM approach with agile 
management system. The priority values stand for satisfiability of the goal according to the stakeholder. The knowledge management gives reasoning. Providing reasons for giving a priority value makes the stakeholder more sensible for conveying that value.

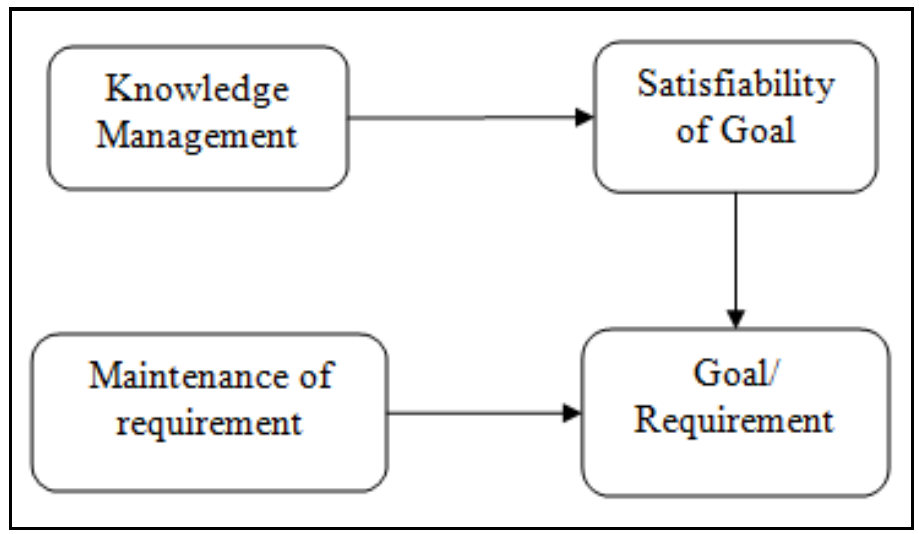

Figure 3. Agile Management System with Knowledge management

\section{Conclusions}

Plans regarding creating learning based and information management devices to maintain a strategic distance from software risks can additionally be obtained from the web applications. In this paper, we provided architecture and algorithmic development approach to implement realtime application to facilitate software risk prediction and mitigation based on knowledge management system with reference to "risk database" of any software company. A number of these devices are focused around long ago caught learning that is bundled and effectively dispersed and connected. Different devices help with learning management in that they give a backing to a particular undertaking inside information management. Few apparatuses give the key stage to information management on top of which supportive provisions might be constructed. Consequently it is certain sight that we can manufacture better worldwide software risk relief apparatus to evade software venture failure.

\section{ACKNOWLEDGEMENTS}

The authors would like to thank the support throughout the research from different researchers and colleagues.

\section{REFERENCES}

1. Pirkkalainen, Henri, and Jan M. Pawlowski. "Global social knowledge Management understanding barriers for global workers utilizing social software." Computers in Human Behavior 30 (2014): 637-647.

2. Smite, Darja, et al. "Empirical evidence in global software engineering: a systematic review." Empirical software engineering 15.1 (2010): 91-118.

3. Dingsoyr, Torgeir, and Darja Smite. "Managing Knowledge in Global Software Development Projects." (2013): 1-1.

4. Beecham, Sarah, et al. "Who are we doing Global Software Engineering research for " Global Software Engineering (ICGSE), 2013 IEEE 8th International Conference on. IEEE, 2013.

5. Dingsoyr, Torgeir, et al. "A decade of agile methodologies: Towards explaining agile software development." Journal of Systems and Software 85.6 (2012): 1213-1221. 
International Journal of Managing Public Sector Information and Communication Technologies (IJMPICT)

Vol. 6, No. 1, March 2015

6. Asif, Muhammad, Jamil Ahmed, and Abdul Hannan. "Software Risk Factors: A Survey and Software Risk Mitigation Intelligent Decision Network Using Rule Based Technique." Proceedings of the International MultiConference of Engineers and Computer Scientists. Vol. 1. 2014.

7. Bjorn, Pernille, et al. "Global software development in a CSCW perspective." Proceedings of the companion publication of the 17th ACM conference on Computer supported cooperative work and social computing. ACM, 2014.

8. Highsmith, Jim. Adaptive software development: a collaborative approach to managing complex systems. Addison-Wesley, 2013

9. Yanzer Cabral, Anderson R., Marcelo Blois Ribeiro, and Rodrigo Perozzo Noll. "Knowledge Management in Agile Software Projects: A Systematic Review." Journal of Information and Knowledge Management 13.01,2014.

10. Neves, Sandra Miranda, et al. "Knowledge-Based Risk Management: Survey on Brazilian Software Development Enterprises." Advances in Information Systems and Technologies. Springer Berlin Heidelberg, 55-65,2013.

11. Grant, Robert M. "Nonaka's Dynamic Theory of Knowledge Creation"(1994): Reflections and an Exploration of the Ontological Dimension." Towards Organizational Knowledge: The Pioneering Work of Ikujiro Nonaka 77,2013.

12. Huang, Hung-Chun, et al. "Accelerating Knowledge Adoption: Information Systems Change Management?." Approaches and Processes for Managing the Economics of Information Systems 253,2014 .

13. Nonaka, Ikujiro, et al. "Dynamic fractal organizations for promoting knowledge-based transformation?A new paradigm for organizational theory." European Management Journal 32.1, pp 137-146,2014.

14. Birk, Wolfgang, Miguel Castao, and Andreas Johansson. "An application software for visualization and control configuration selection of interconnected processes." Control Engineering Practice 26 (2014): 188-200.

15. Vasquez-Bravo, Diana-Marcela, et al. "Knowledge management acquisition improvement by using software engineering elicitation techniques." Computers in Human Behavior 30 pp: 721$730,2014$.

16. de Gea, Juan Manuel Carrillo, et al. "Reusing requirements in global software engineering." Managing requirements knowledge. Springer Berlin Heidelberg, 2013. 171-197.

17. Franch, X., et al. "Constructing and Using Software Requirement Patterns." Managing requirements knowledge. Springer Berlin Heidelberg, 2013. 95-116.

18. Noll, John, Sarah Beecham, and Ita Richardson. "Global software development and collaboration: barriers and solutions." ACM Inroads 1.3 pp: 66-78,2010.

19. Kavitha, R. K., and Irfan Ahmed. "A knowledge management framework for agile software development teams." Process Automation, Control and Computing (PACC), 2011 International Conference on. IEEE, 2011.

20. Jadhav, Anil S., and Rajendra M. Sonar. "Framework for evaluation and selection of the software packages: A hybrid knowledge based system approach.” Journal of Systems and Software 84.8 pp: 1394-1407,2011.

21. Shruti Patil and Roshani Ade. "Software Requirement Engineering Risk Prediction Model." International Journal of Computer Applications 102.2 pp:1-6,2014.

22. Shruti Patil and Roshani Ade. "Secured Cloud Support For Global Software Requirement Risk Management." International Journal of Software and Application; Vol.5, No.6,pp: 23-29,2014.

23. Shruti Patil and Roshani Ade. "Cloud Data Security for Goal Driven Global Software Engineering Projects" International Conference on Information and Communication Technologies (ICICT 2014) Procedia Computer Science, Elsevier 2014

24. Shruti Patil and Roshani Ade. "A Software Project Risk Analysis Tool Using Software Development Goal Modeling Approach" Systems Design and Intelligent Applications Proceedings of Second International Conference INDIA 2015, Information Systems Design and Intelligent Applications Volume 2, Series: Advances in Intelligent Systems and Computing , volume 340 ; Springer (Verlag), 2015 Pp: 767-777

25. Shruti Patil and Roshani Ade.. "Generic Approach for Goal driven Software Requirement Risk Management." Communications on Applied Electronics, 1.3, pp: 18-21,2015 